\title{
Materials for High-Speed Transport Systems
}

\author{
By Nataliya Kazantseva*
}

Titanium aluminides are promising perspective materials which provide a unique combination of physical and mechanical properties for high-speed transport systems, like sport cars, racing cars and high-speed trains. These materials are characterized by good strength at temperatures up to 650 OC ( $600 \mathrm{MPa})$, but poor roomtemperature plasticity ( 1-2 \%). The latter property limits their commercial applications. The efforts aimed at the improvement of the plasticity of these alloys include both the design of new alloys and new methods of their production. A comparative study of the phase content, structure and the mechanical properties of the different titanium aluminides are presented. We study the influence of the crystallization conditions on the microstructure and mechanical properties of the TiAl- and Ti3Al- based alloys prepared by the special method of pulsed volume pressing (PVP) and the Ti2AlNb-base alloys. The factors responsible for the successful structure of TiAl-alloys with high mechanical properties were found. The cooling rate that varies in the mold with different heat capacities $(0.385 \mathrm{cal} / \mathrm{g} K$ for copper and $0.12 \mathrm{cal} / \mathrm{g} K$ for steel) substantially affects the grain size, the uniformity of its distribution and the lamella thickness. In the Ti3Al-base alloy high rates of cooling allow conserving "soft" plates of $\beta_{0}$-phase. The mechanical properties and structure of the stable and metastable phases in the Ti2AlNb-base alloys under severe plastic deformation (shear under pressure) were also studied.

Keywords: Titanium aluminides, structure, phase transformation, metastable phases, severe plastic deformation

\section{Introduction}

The development of the high-speed transportation systems is one of the most interesting scientific directions. It is known that the materials for which produce the details for the sport cars, racing cars, high-speed trains, should work at a high temperature, pressure, and in aggressive media. Low weight is also important for these materials because it reduces fuel consumption. Titanium aluminides are the promising high temperature light weight materials which are an alternative to conventional heavy heat-resistant steels, cobalt and nickel super-alloys for automotive and aircraft engines. Titanium aluminides posses attractive properties for applications under high thermal and mechanical loads, e.g. a low specific weight, good resistance to oxidation and burn resistance at temperatures up to $1200 \mathrm{~K}$, high elastic stiffness and enhanced high temperature strength, but poor room-temperature plasticity (1-2\%) (Kim, 1989; Naka et al., 1992; Appel et al., 2011). The last fact complicates their commercial application. The improvement of the plasticity of these alloys includes both the design of new alloys and new methods of production

*Senior Research Scientist, Institute of Metal Physics, Ural Division of RAS, Russia. 
(Kazantseva et al., 2001; Kawabata et al., 1998, Kim, 2014). The optimum combination of properties can be attained by the formation of a specific structure, such as a fully lamellar two-phase $\mathrm{TiAl} / \mathrm{Ti}_{3} \mathrm{Al}$ structure with controlled content of $\gamma$ and $\alpha_{2}$ phases (Kim, JOM, 1989; Yamaguchi, Mat. Sci. and Technol.,1992). However, the ultimate strength, plasticity, and fracture behavior of such alloys are very sensitive to the orientation and microstructure of lamellae. It is known that a small addition of niobium or vanadium as a beta-stabilizer to the alloys based on $\mathrm{TiAl}$ and $\mathrm{Ti}_{3} \mathrm{Al}$ increases roomtemperature plasticity (Kawabata et al., 1998; Yao et al., 1995). The orthorhombic $\mathrm{O}$ (NaHg-type, $\mathrm{Cmcm}$ ) phase of composition $\mathrm{Ti}_{2} \mathrm{AlNb}$, is ordered by three elements: $\mathrm{Ti}, \mathrm{Al}$, and $\mathrm{Nb}$, forms in the alloys which contain $\geq 11$ at. $\% \mathrm{Nb}$. $\mathrm{Ti}_{2} \mathrm{AlNb}$-base alloys have a modified super- $\alpha_{2}$ structure and differ in phase compositions and mechanical properties from the TiAl- base and $\mathrm{Ti}_{3} \mathrm{Al}$-base alloys (Bendersky et al., 1994; Boehlert et al., 1999; Kazantseva et al., 2002-2003). The improvement of the plasticity of the alloys on the base of titanium aluminides of different ages can be also achieved by special structure creation or by the use of the metastable phases. Methods of severe plastic deformation, such as shear under pressure, shock-wave loading, and equal channel angular pressing, are used successfully to obtain fine-grained structures of materials, which substantially improves their mechanical properties (Greenberg et al., 2005; Kazantseva et al., 2003).

In this report, we present a short review of the structure and mechanical properties studies of the titanium aluminides with the different chemical compositions.

\section{Experimental}

The $\mathrm{TiAl}$ and $\mathrm{Ti}_{3} \mathrm{Al}$ samples were prepared by the experimental method of pulsed forging (pulsed volume pressing, PVP). The ternary alloys $\left(\mathrm{Ti}_{2} \mathrm{AlNb}-\right.$ base) were prepared by arc melting under an argon atmosphere using titanium (99.98\%), high-purity aluminum (99.9\%), and niobium $(99.9 \%)$. The chemical compositions of the alloys under study are given in Table 1.

Table 1. Chemical Composition (at. \%) of the Alloys under Study

\begin{tabular}{|c|c|c|c|c|c|c|}
\hline No & $\mathrm{Ti}$ & $\mathrm{Al}$ & $\mathrm{V}$ & $\mathrm{Nb}$ & $\mathrm{Mo}$ & $\mathrm{Cr}$ \\
\hline 1 & base & 48 & 1 & - & & \\
\hline 2 & base & 45 & 1 & - & & \\
\hline 3 & base & 46 & 1.3 & & & \\
\hline 4 & base & 34 & - & 1.6 & 0.5 & 0.3 \\
\hline 5 & base & 22 & - & 26.6 & - & - \\
\hline
\end{tabular}

For the X-ray study samples of $0.5 \mathrm{~mm}$ in thickness were cut from ingots and electro - polished by electrolyte with $20 \mathrm{ml}$ perchloric acid and $80 \mathrm{ml}$ acetic acid $\left(\mathrm{T}=-15^{\circ} \mathrm{C}, \mathrm{V}=40 \mathrm{~V}\right)$. The $\mathrm{X}$-ray diffraction examination was performed using a DRON-3 diffractometer with $\mathrm{Cu} \mathrm{K} \alpha$ radiation, $\lambda=0.15478$ $\mathrm{nm}$; we used the rotation of the sample. The phase composition of alloys was 
determined using an ASTM standard X-ray Database. The microstructure was examined using a Neophot-2 optical microscope and a JEM-200CX electron microscope. Mechanical tests of samples $3 \times 3 \times 4,5 \mathrm{~mm}$ in size were performed in the air using an INSTRON machine at a strain rate of $0,05 \mathrm{~mm} / \mathrm{min}$. Severe plastic deformations were done by the methods shear at room temperature under quasi-hydrostatic pressure using Bridgman anvils ( $\mathrm{P}=10 \mathrm{GPa})$.

\section{Results and Discussion}

The alloys after the pulsed forging did not have a texture or a dendrite structure characteristic of cast $\mathrm{TiAl}$ and $\mathrm{Ti}_{3} \mathrm{Al}$ (Figure 1). According to the $\mathrm{X}$ ray results, the TiAl-base alloys (Alloys 1-3) contained two ordered phases $\operatorname{TiAl}\left(\gamma, \mathrm{L} 1_{0}\right)$ and $\mathrm{Ti}_{3} \mathrm{Al}\left(\alpha_{2}, \mathrm{D} 0_{19}\right)$, and were in a polycrystalline state. Alloy 4 consisted of three ordered phases $\beta_{0}(\mathrm{~B} 2), \omega\left(\mathrm{B} 8_{2}\right)$, and $\alpha_{2}\left(\mathrm{D} 0_{19}\right)$ (Figures 2$)$.

Figure 1. The Cast Sample after Pulsed Forging

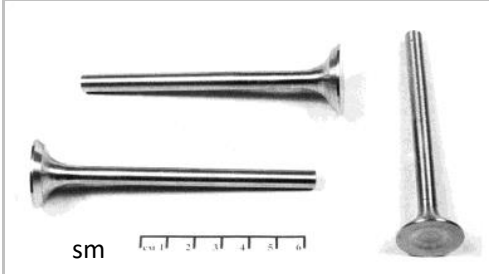

Figure 2. X-ray Diffraction Pattern of the Samples after Pulsed Forging: aAlloy 1; b-Alloy 2; c-Alloy 3; d-Alloy 4
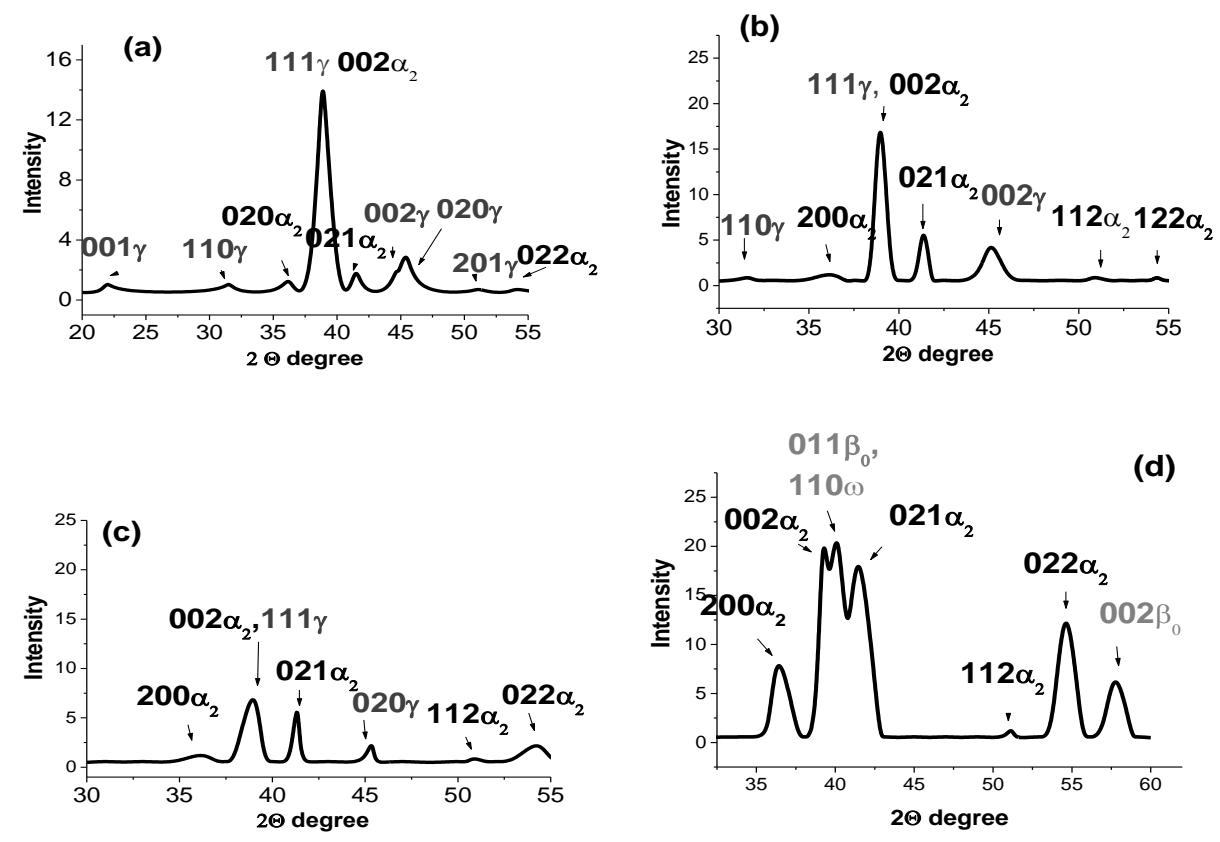

The structure of Alloy 1 consisted on uniform equiaxial grains with an average size of about $40 \mu \mathrm{m}$. The lamellae inside the grains were distributed uniformly and had a small width: 0.02 to $0.06 \mu \mathrm{m}$ for $\alpha_{2}$ lamellae and 0.06 to 
$0.2 \mu \mathrm{m}$ for $\gamma$ lamellae. The structure of Alloy 2 consisted on grains with a different form. The average size of the grains was about $60 \mu \mathrm{m}$. The lamellar structure formed in the middle of the grains; $\gamma$ and $\alpha_{2}$ lamellae were $\approx 0.3$ and $0.08 \mu \mathrm{m}$ wide, respectively. The zone of the elongated grains occupied the most part of the Alloy 3. The central part of the grains had thin lamellae: for that were $\gamma \approx 0.2 \mu \mathrm{m}$ and for $\alpha_{2} \approx 0.03 \mu \mathrm{m}$ in wide width. According to the TiAl equilibrium diagram the structure of Alloy 4 must have $\alpha_{2}$ singe phase content. $\beta_{0}$-Phase forms at high temperature and transforms to low-temperature $\alpha_{2}$ - phase during usual cooling of the alloy. We suppose that the addition of the beta stabilized elements $(\mathrm{Nb}, \mathrm{Mo}$, and $\mathrm{Cr})$ and the high rate of cooling of the alloy allowed us to serve $\beta_{0}$-phase as unstable phase at room temperature. The structure of this alloy consisted on of grains with Widmanstatten a structure inside of them (Figure 3). The grain sizes of the grains were from 50 up to 200 $\mu \mathrm{m}$. We also found the small particles of $\omega$-phase $\left(\mathrm{B} 8_{2}\right)$ inside of the $\beta_{0}$ plates.

Figure 3. Microstructure of the Alloys under Study, TEM: $a$-Alloy 1; $b$-Alloy 2; c-Alloy 3; d-Alloy 4
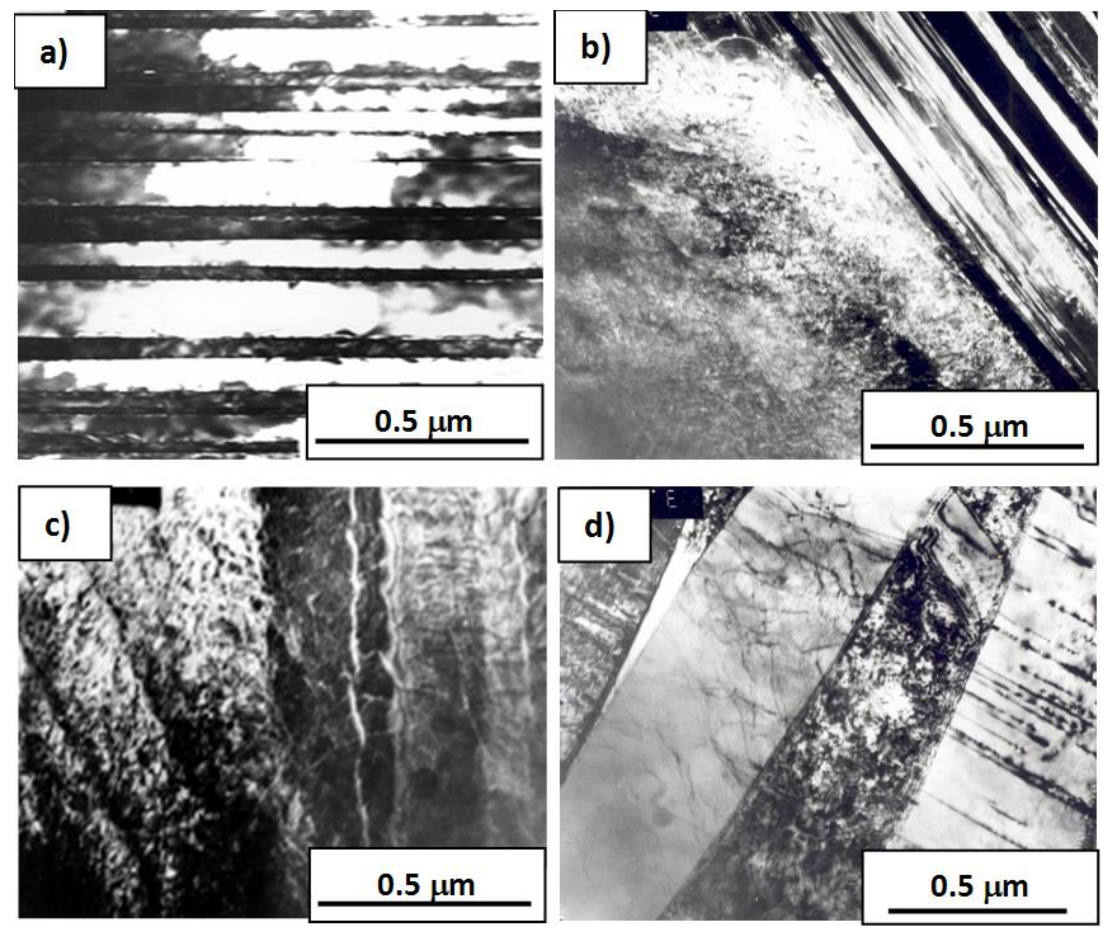

Alloys 1-4 had high strength characteristics (Table 2). A high value of the yield stress $\sigma_{0.2} \geq 700 \mathrm{MPa}$ suggested the presence of a hard deformation mode. 
Table 2. Results of the Mechanical Tests of the Alloys under Study

\begin{tabular}{|c|c|c|c|c|c|}
\hline No & $\begin{array}{c}\text { Compressive } \\
\text { strength } \\
\sigma_{\mathrm{b}}{ }^{\text {comp. }} \\
\mathrm{M \Pi a} \\
\mathrm{t}=20^{\circ} \mathrm{C}\end{array}$ & $\begin{array}{c}\text { Yield } \\
\text { stress } \\
\sigma_{0,2}{ }^{\text {comp }}, \\
\text { MПa, } \\
\mathrm{t}=20^{\circ} \mathrm{C}\end{array}$ & $\begin{array}{c}\text { Ductility } \\
\varepsilon, \%, \\
\mathrm{t}=20^{\circ} \mathrm{C}\end{array}$ & $\begin{array}{c}\text { Compressive } \\
\text { strength } \\
\sigma_{\mathrm{b}}^{\text {tens }}, \mathrm{M} \Pi \mathrm{a}, \\
\mathrm{t}=20^{\circ} \mathrm{C} / \\
800^{\circ} \mathrm{C}\end{array}$ & $\begin{array}{c}\text { Ductility } \\
\varepsilon, \%, \\
\mathrm{t}=20^{\circ} \mathrm{C} / \\
800^{\circ} \mathrm{C}\end{array}$ \\
\hline 1 & 1088 & 685 & 32.6 & - & - \\
\hline 2 & 1184 & 1007 & 17 & - & - \\
\hline 3 & 1030 & 844 & 18 & $262 / 652$ & $0,6 / 1,7$ \\
\hline 4 & 1920 & 1314 & 10 & - & - \\
\hline $\begin{array}{c}4 \\
\text { (annealing) }\end{array}$ & 1700 & 872 & 19 & - & - \\
\hline
\end{tabular}

It is known that the alloys were prepared in the laboratory by zone melting and had an oriented lamellar structure (polysynthetically twinned crystals, PST) and very high mechanical properties at a grain size varying between 25 and $50 \mu \mathrm{m}$ (Naka, 1992). The maximum strength of the PST TiAl alloys at room temperature is $1800 \mathrm{MPa}$ at a plasticity of $23 \%$, the $\gamma$ interlamellar spacing in the alloy is $1.4 \mu \mathrm{m}$. In turn, the strength of the polycrystalline TiAl samples prepared by complex thermomechanical treatment and having a nonoriented lamellar structure is as small as $600 \mathrm{MPa}$, and the plasticity of the alloy is about 6\% (Kim, 1989; Yamaguchi, 1992). Compared to the "pure" PST TiAl alloys, the PST alloys containing vanadium exhibit a higher plasticity upon both tension and compression. The plasticity of the Ti-48,4at.\% Al0,6 at. $\% \mathrm{~V}$ alloys upon compression reaches $28 \%$. The vanadium-containing alloys are characterized by a more uniform distribution of $\alpha_{2}$ lamellae and by a thickness of $\gamma$ lamellae of 0.2-2 $\mu \mathrm{m}$ (Yao, 1995).

According to (Yamaguchi, 1992) titanium aluminides with oriented lamellar structure have bad plasticity when shear deformation proceeds across the lamellar boundaries (hard mode). When shear deformation occurs parallel to the lamellar boundaries (easy mode) plasticity increases, but strength decreases. Because of that it is difficult to create all construction detail with high mechanical properties from oriented lamella titanium aluminides. This means that the almost oriented lamellar structure of the titanium aluminides received in this study is more preferable then the oriented one.

The data obtained was compared with the strength characteristics of an orthorhombic phase $\mathrm{Ti}_{2} \mathrm{AlNb}$-base alloy (Alloy 5). According to the X-ray analysis, the phase composition of Alloy 5 consisted of two phases $\mathrm{O}^{\text {enriched }}+\mathrm{O}^{\text {depleted }}$ which formed, as we supposed, after first quenching (Figure 4). The parameters of the crystal lattices of these phases were calculated as follows: $a 1=0.6102 \mathrm{~nm}, b 1=0.9920 \mathrm{~nm}, c 1=0.4642 \mathrm{~nm}$ and $a 2=0.6096 \mathrm{~nm}$, $b 2=0.9599 \mathrm{~nm}, c 2=0.4642 \mathrm{~nm}$.

This alloy had a plate structure (Figure 5) which was obtained by the special thermal treatment conditions $\left(1200^{\circ} \mathrm{C}-1 \mathrm{~h}\right.$., water quenching $+800{ }^{\circ} \mathrm{C}$ 100h., furnace cooling $+700{ }^{\circ} \mathrm{C}-110 \mathrm{~h}$., furnace cooling $+500{ }^{\circ} \mathrm{C}-100 \mathrm{~h}$. furnace cooling). We used the various heat treatments within the temperature area of 
O-phase existence to try to align the phase composition of the alloy, but the two O-phases structure was very stable.

Figure 4. X-ray Diffraction Pattern of Sample 5

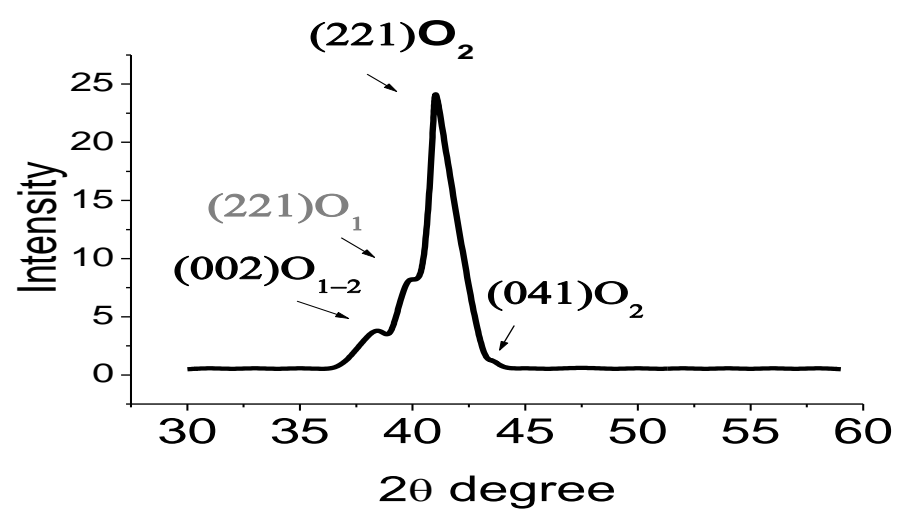

Figure 5. Microstructure of Alloy 5, TEM: a- the Dark-field Image in (020)O; b-SAED Pattern to a). Zone Axis[111]O

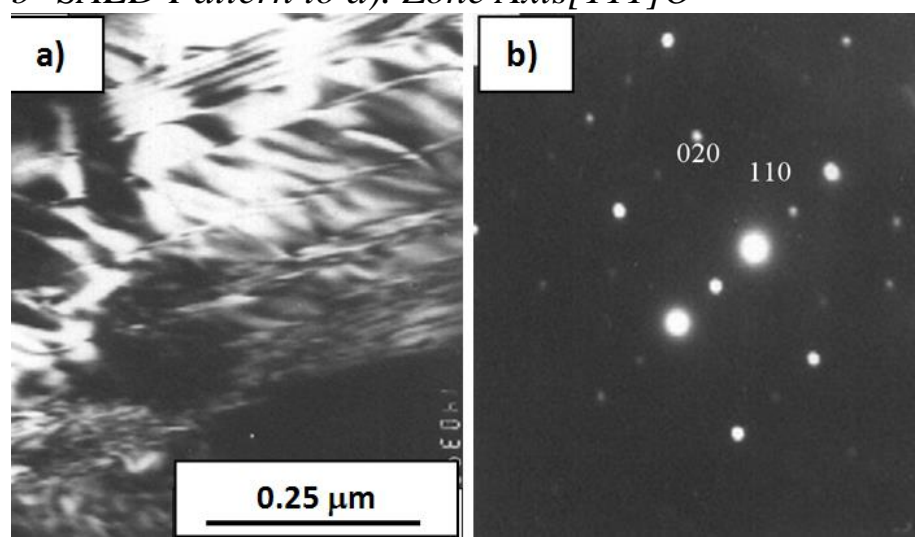

The strength characteristics of Alloy 5 with the orthorhombic phases only were as follows: $\sigma_{\mathrm{b}}{ }^{\text {comp. }} \approx 1381 \mathrm{MPa}, \varepsilon \approx 19 \%$. According to the literature data, the single phase (O-phase) alloys with the equaixed grains have very low mechanical properties, such as $\sigma_{\mathrm{b}}{ }^{\text {comp. }} \approx 704 \mathrm{MPa}, \varepsilon \approx 1.09 \%$ (Boehlert, 1999). Thus, our results show that the single phase (O-phase) alloys with the stable plate structure have higher mechanical properties in compare with the structure with the equaixed grains. Also, one can say that the mechanical properties of the $\mathrm{Ti}_{2} \mathrm{AlNb}$-base alloy are higher than the properties of the TiAl-base alloys (Alloys 1-3) and closer to the mechanical properties of the two phases (stable $\alpha_{2}$ and unstable $\beta_{0}$ ) in the $\mathrm{Ti}_{3} \mathrm{Al}$-base alloy (Alloy 4 ).

Lines, which did not belong to the orthorhombic O-phase, appeared in diffraction patterns of Alloy 5 already after it was deformed to $\varepsilon=0.9$ (hydrostatic compression). After deformation $\varepsilon=4.7$, the intensity of the lines belonging to the unknown phases increased. After deformation to $\varepsilon=6.3$, the $\mathrm{O}$ phase lines were still observed in the X-ray diffraction patterns, however their 
intensity was substantially lower than that of the unknown-phase lines. After deformation to $\varepsilon=7.6$, no lines of orthorhombic phases were observed; the $X$ ray diffraction pattern exhibited reflections of only the unknown phases (Figure 6). Processing X-ray diffraction data by the DMPLOT program showed that severe plastic deformation leads to an order-disorder phase transformation with the formation of fine particles of two orthorhombic phases, namely, a B19 phase disordered for niobium and a completely disordered A20 phase. An analysis of the variations of the line-intensity ratio of the B19 and A20 phases allows us to conclude that, as the degree of deformation increases, the content of the B19 phase decreases, whereas the content of the A20 phase increases.

Severe deformation made for an evolution of new structure regions with new mechanical properties. Such regions may form as nano-scale fluctuation under usual deformation processes. The formation of the disordered phases effects on the strength characteristics of the alloy; microhardness of Alloy 5 was measured as follows: $\mathrm{H}_{100}=5869 \pm 40 \mathrm{MPa}$ for the initial state and $\mathrm{H}_{100}=$ $4774 \pm 40 \mathrm{M \Pi a}$ for alloy after deformation $\varepsilon=7.6$.

Figure 6. X-ray Diffraction Pattern of Alloy 5 after Shear under Pressure ( $\varepsilon=7.6)$

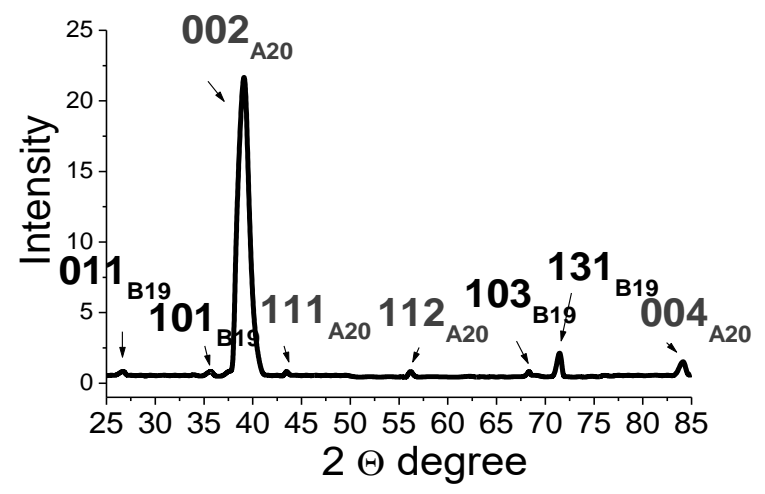

TEM studies showed that with the increase of the degree of deformation the structure of the alloy becomes very fine and contains only the B19 and A20 phases. The average size of the fragments determined from dark-field images is equal to 20-30 nm (Figure 7).

Figure 7. Microstructure of Alloy 5 after Shear under Pressure, TEM: $a$ - the Dark-field Image in (110)A20; b-SAED Pattern to a)
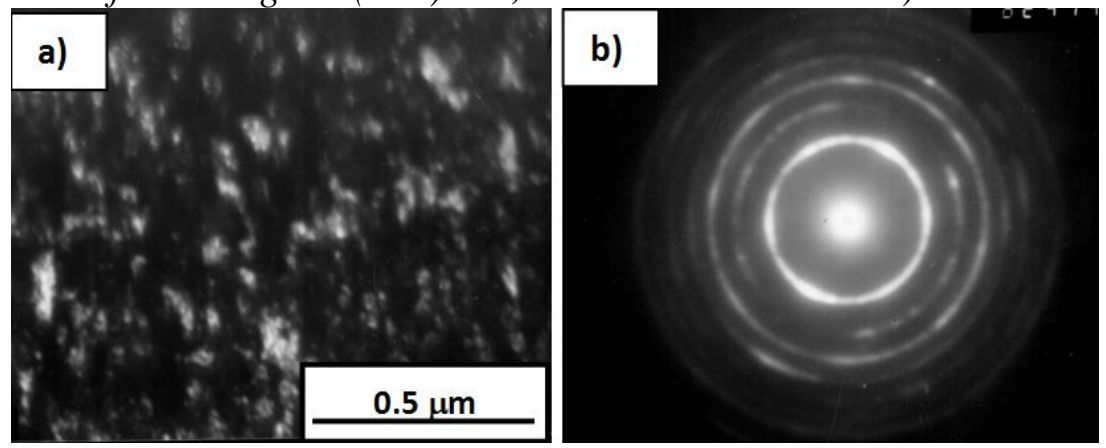


\section{Conclusions}

The study of the microstructure and mechanical properties of the titanium aluminides of the different ages leads to the following important conclusions:

1. The cooling rate, vibration, and addition pressing under crystallization were used in the experimental method. These external factors substantially affect the grain size, the uniformity of its distribution and the lamella thickness in TiAl-base alloys and should be taken into account for obtaining the alloys with the optimal structure and high mechanical properties.

2. In the $\mathrm{Ti}_{3} \mathrm{Al}$-base alloy high rate of cooling allows conserving "soft" plates of high-temperature $\beta_{0}$ phase with the metastable $\omega$ phase inside them. Additional aging at $900^{\circ} \mathrm{C}-5 \mathrm{~h}$. provides the increase of the plasticity by dissolution of the brittle $\omega$-phase.

3. High temperature heat treatments allow obtaining the structure which is responsible for high strength/plasticity relation in the $\mathrm{Ti}_{2} \mathrm{AlNb}$-base alloys.

4. In the $\mathrm{Ti}_{2} \mathrm{AlNb}$-base alloys, severe deformation causes phase transformations, which occur at a fixed number. The resulting phase transformation under severe deformation in these alloys is order-disorder phase transformation with retention of crystal singony.

\section{Acknowledgments}

This work was supported by the Russian Foundation for Basic Research, project no. 14-18-00108.

\section{References}

Appel F., Paul J.D.H., Oehring M. 2011. Gamma Titanium Aluminide Alloys: Science and Technology, Wiley-VCH Verlag \& Co, Weinheim, Germany, 762 p. ISBN: 978-3-527-31525-3

Greenberg, B.A., Kazantseva, N.V., Pilugin, V.P., Shorokhov, E.V. 2005. In monograph Severe Plastic Deformation: Toward Bulk Production of Nanostructured Materials, Ed. Altan Burhanettin. Nova Science Publishers, Inc., New-York. Ch. 2.4, 169-182. ISBN: 1-59454-508-1.

Bendersky, L.A., Roytburd, A., and Boettinger, W.J. 1994. Phase Transformations in the (Ti, Al) $3 \mathrm{Nb}$ Section of the Ti-Al-Nb System, I. Microstructural Predictions Based on a Subgroup Relation between Phases. Acta Metal. Mater. 42, 7 (July 1994), 2323-2335. DOI= http://dx.doi.org/ 10.1016/0956-7151(94)90311-5

Boehlert, C.J., Majumdar, Seetharaman, B.S., Seetharaman V. and Miracle, D.B. 1999. The Microstructural Evolution in Ti-Al-Nb O + BCC Orthorhombic 
Alloys. Part 1. Metall. Mater. Trans. A 30A 10 (October 1999), 2305-2323. DOI= http://dx.doi.org/10.1007/s11661-999-0240-4

Kazantseva, N.V., Greenberg, B.A., Popov, A.A., and Shorokhov, E.V. 2003. Phase transformations in $\mathrm{Ni}_{3} \mathrm{Al}, \mathrm{Ti}_{3} \mathrm{Al}$ and $\mathrm{Ti}_{2} \mathrm{AlNb}$ intermetallics under shock-wave loading. J.Phys. IV France. 110, 923-928. DOI= http://dx.doi.org/10.1051/ jp4:20020812

Kazantseva, N.V., Volkov, A.E., Greenberg, B.A., Popov, A.A., and Yurovskikh V. V. 2001. Microstructure of the Ti(Al,V) Intermetallic Compound Melted under Elevated Pulsed Pressure Applied by Various Regimes. Phys. Met. Metallogr. 91, 2 (February 2001), 173-178.

Kazantseva, N.V., Greenberg, B.A., Demakov, S.L., Popov, A.A., Romanov, E.P., Ribin, V.V. 2002. Microstructure and plastic deformation of the ortochrombic $\mathrm{Ti}_{2} \mathrm{AlNb}$. I. Formation of the polydomen structure. Phys. Met. Metallogr. 93, 3 (March 2002), 269-270.

Kazantseva, N.V., Greenberg, B.A., Gulyaeva, N.P., Demakov, S.L., Pilyugin, V.P., Popov, A. A., Romanov, E. P., Shorokhov, E. P., and Rybin, V. V. 2003. Microstructure and plastic deformation of the ortochrombic Ti2AlNb. II. Structural and phase transformations under intensive plastic deformation. Phys. Met. Metallogr. 96, 4 (April 2003), 368-377.

Kawabata, Takeshi, Fukai, Hideaki, Izumi, Osamu. 1998. Effect of ternary additions on mechanical properties of TiAl. Acta Materialia. 46, 6 (March 1998), 21852194. http://dx.doi.org/10.1016/S1359-6454(97)00422-9

Kim, Young-Won. 1989. Intermetallic alloys based on gamma titanium aluminide. JOM. 41, 7 (July 1989), 24-30. DOI= http://dx.doi.org/10.1007/BF03220267

Kim, Young-Won, Smarsly W., Junpin Lin J., Dimiduk D., Appel F. 2014. Gamma Titanium Aluminide Alloys 2014. Wiley-VCH Verlag \& Co, Weinheim, Germany, TMS 224p. ISBN: 978-1-118-99558-7

Naka, S., Tomas, M., and Khan, T. 1992. Potential and prospects of some intermetallic compounds for structural applications. Mat. Sci. and Technol. 8, 4 (April 1992), 291-298.

Yamaguchi, M. High temperature intermetallics - with particular emphasis on TiAl.1992. Mat. Sci. and Technol. 8, 4 (April 1992), 299-307.

Yao, K.F., Iniu, H., Kishida, K., and Yamaguchi, M. 1995. Plastic deformation of Vand $\mathrm{Zr}$-alloyed PST TiAl in tension and compression at room temperature. Acta Metall. Mater. 43, 1075-1086. DOI= http://dx.doi.org/10.1016/0956-7151(94) 00317-B 
